\title{
Socioeconomic inequalities in diabetes mellitus across Europe at the beginning of the 21st century
}

\author{
A. Espelt • C. Borrell • A. J. Roskam • \\ M. Rodríguez-Sanz • I. Stirbu • A. Dalmau-Bueno • \\ E. Regidor • M. Bopp • P. Martikainen • M. Leinsalu • \\ B. Artnik • J. Rychtarikova $\cdot$ R. Kalediene $\cdot$ \\ D. Dzurova • J. Mackenbach • A. E. Kunst
}

Received: 20 May 2008 /Accepted: 7 August 2008 / Published online: 9 September 2008

(C) Springer-Verlag 2008

\begin{abstract}
Aims/hypothesis The aim of this study was to determine and quantify socioeconomic position (SEP) inequalities in diabetes mellitus in different areas of Europe, at the turn of the century, for men and women.

Methods We analysed data from ten representative national health surveys and 13 mortality registers. For national health surveys the dependent variable was the presence of diabetes by self-report and for mortality registers it was death from diabetes. Educational level (SEP), age and sex were independent variables, and age-adjusted prevalence ratios (PRs) and risk ratios (RRs) were calculated.
\end{abstract}

A. Espelt $(\bowtie) \cdot$ C. Borrell $\cdot$ M. Rodríguez-Sanz .

A. Dalmau-Bueno

Agència de Salut Pública de Barcelona,

Plaça Lesseps 1,

08023 Barcelona, Spain

e-mail: aespelt@aspb.cat

C. Borrell

Department of Experimental and Health Science,

Universitat Pompeu Fabra,

Barcelona, Spain

C. Borrell · M. Rodríguez-Sanz

CIBER Epidemiología y Salud Pública (CIBERESP),

URL: http://www.ciberesp.es

A. J. Roskam - I. Stirbu · J. Mackenbach - A. E. Kunst

Department of Public Health,

Erasmus Medical Center,

Rotterdam, the Netherlands

E. Regidor

Department of Preventive Medicine and Public Health,

Universidad Complutense de Madrid,

Madrid, Spain
Results In the overall study population, low SEP was related to a higher prevalence of diabetes, for example men who attained a level of education equivalent to lower secondary school or less had a PR of 1.6 (95\% CI 1.4 1.9) compared with those who attained tertiary level education, whereas the corresponding value in women was 2.2 (95\% CI 1.9-2.7). Moreover, in all countries, having a disadvantaged SEP is related to a higher rate of mortality from diabetes and a linear relationship is observed. Eastern European countries have higher relative inequalities in mortality by SEP. According to our data, the RR of dying from diabetes for women with low a SEP

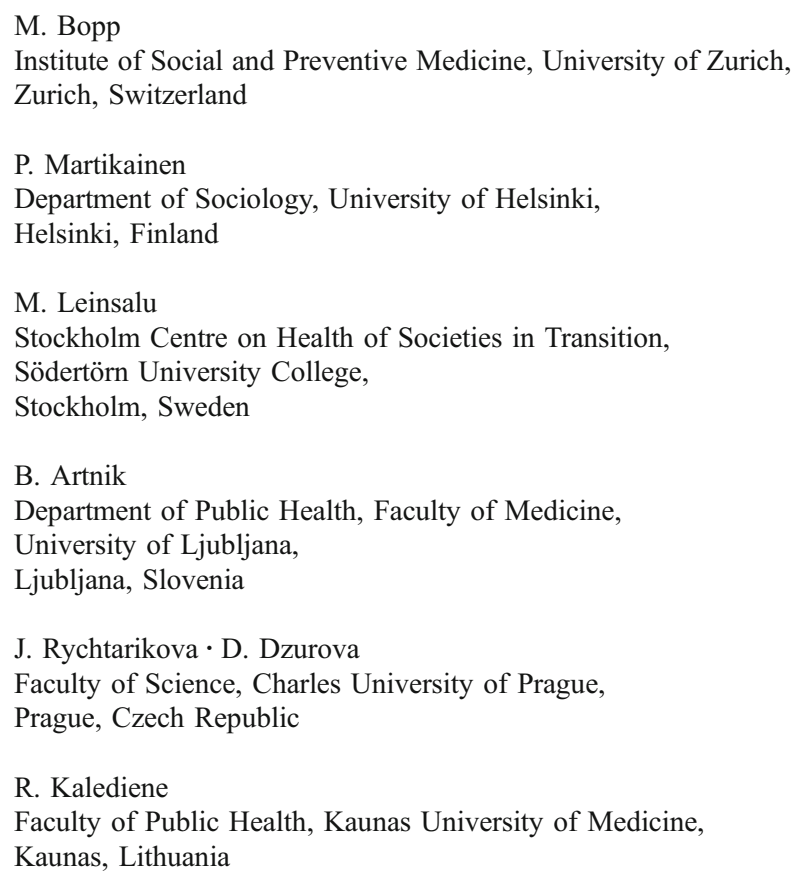

R. Kalediene

Faculty of Public Health, Kaunas University of Medicine, Kaunas, Lithuania 
is $3.4(95 \%$ CI $2.6-4.6)$, while in men it is $2.0(95 \%$ CI 1.7-2.4).

Conclusions/interpretation In Europe, educational attainment and diabetes are inversely related, in terms of both morbidity and mortality rates. This underlines the importance of targeting interventions towards low SEP groups. Access and use of healthcare services by people with diabetes also need to be improved.

Keywords Diabetes $\cdot$ Europe $\cdot$ Socioeconomic inequalities

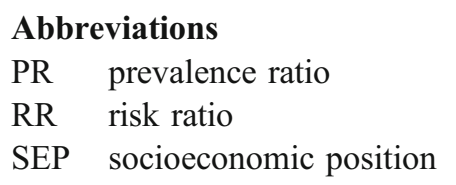

\section{Introduction}

Socioeconomic position (SEP) refers to the social and economic factors that influence what positions individuals or groups hold within the structure of a society, such as educational level, income or wealth. Socioeconomic inequalities in health are the differences in opportunities for maintaining good health between people with different SEPs. [1]. Several studies in Europe have analysed the relationship between socioeconomic inequalities and chronic diseases $[2,3]$ or mortality [4-6] and found an association between health and socioeconomic position - among populations of disadvantaged SEPs the majority of health indicators are worse.

The main factors that relate SEP to health and diabetes are general socioeconomic and political context, working and living conditions, health behaviours and psychosocial factors [7]. Brown et al. described how SEP influences health among persons with diabetes through community factors (e.g. availability of healthy foods, availability of places to exercise), health behaviours (e.g. diet, physical activity), access to healthcare and processes of diabetes care (e.g. measurement of $\mathrm{HbA}_{1 \mathrm{c}}$, smoking cessation) [8].

Some studies have reported that the risk of having diabetes mellitus is associated with a disadvantaged SEP in developed countries as well as in developing countries [9, 10]. This association was shown in both diabetes morbidity studies [3, 8, 10-12] and in diabetes mortality studies [1315]. Recent studies have reported that this association is explained in part by health behaviours and obesity $[8,16-$ 18]. In this respect, cigarette smoking is associated with a low glomerular filtration rate [16] and dietary patterns may influence the risk of type 2 diabetes [17], and these health behaviours, as well as obesity, are related with SEP [19, 20]. Other factors related to inequalities in diabetes mortality are socioeconomic differences in terms of access to and use and quality of healthcare services for patients with diabetes, including diabetes education and diabetes control $[2,8,21]$.

The majority of studies analysing the relationship between diabetes and SEP have only involved one country [9-15], and those that have compared the inequalities in SEP among different countries included several chronic diseases rather than focusing on diabetes alone [3]. The comparison of several European countries can be helpful because country characteristics may be related to the degree of diabetes inequalities. If inequalities in diabetes mortality or prevalence were lesser in some countries compared with elsewhere, closer investigation may suggest ways of reducing these inequalities through health promotion or healthcare policies. Therefore, the aim of the present study was to determine and quantify SEP inequalities in diabetes mellitus in different settings in Europe, at the turn of the century, for men and women, and to compare countries with respect to the magnitude of these inequalities. The main hypotheses of the study were that there are diabetes inequalities in all European countries with respect to mortality as well as morbidity, and that these inequalities are larger among women.

\section{Methods}

Design, population studied and sources of information This is a study of cross-sectional health surveys and longitudinal mortality registers from different areas of Europe. The study population consists of men and women who were resident in the selected countries, aged 30-64 years for the morbidity study (national health surveys) and 30-74 years for the mortality study (mortality registers). We analysed ten representative European national health surveys, all of which were conducted around the year 2000 (seven Western European countries: Finland, Sweden, Norway, Denmark, Belgium, Italy and Spain; three Eastern European countries: Czech Republic, Lithuania and Estonia) and 13 European mortality registers from around the same time (eight Western European sites: Finland, Sweden, Norway, Denmark, Belgium, Switzerland, Turin and Barcelona; five Eastern European sites: Slovenia, Poland, Czech Republic, Lithuania and Estonia). The characteristics of health surveys and registers are shown in Table 1.

Variables In each country, persons with diabetes were identified by self-report based on responses to questions about diabetes. The survey items about diabetes aimed to determine whether the respondent currently had diabetes. In the original surveys this disease was called 'diabetes' (most countries), 'diabetes mellitus' (Belgium) or 'high blood sugar (diabetes)' (Estonia). In Sweden the responses were scored by a general practitioner according to the Interna- 


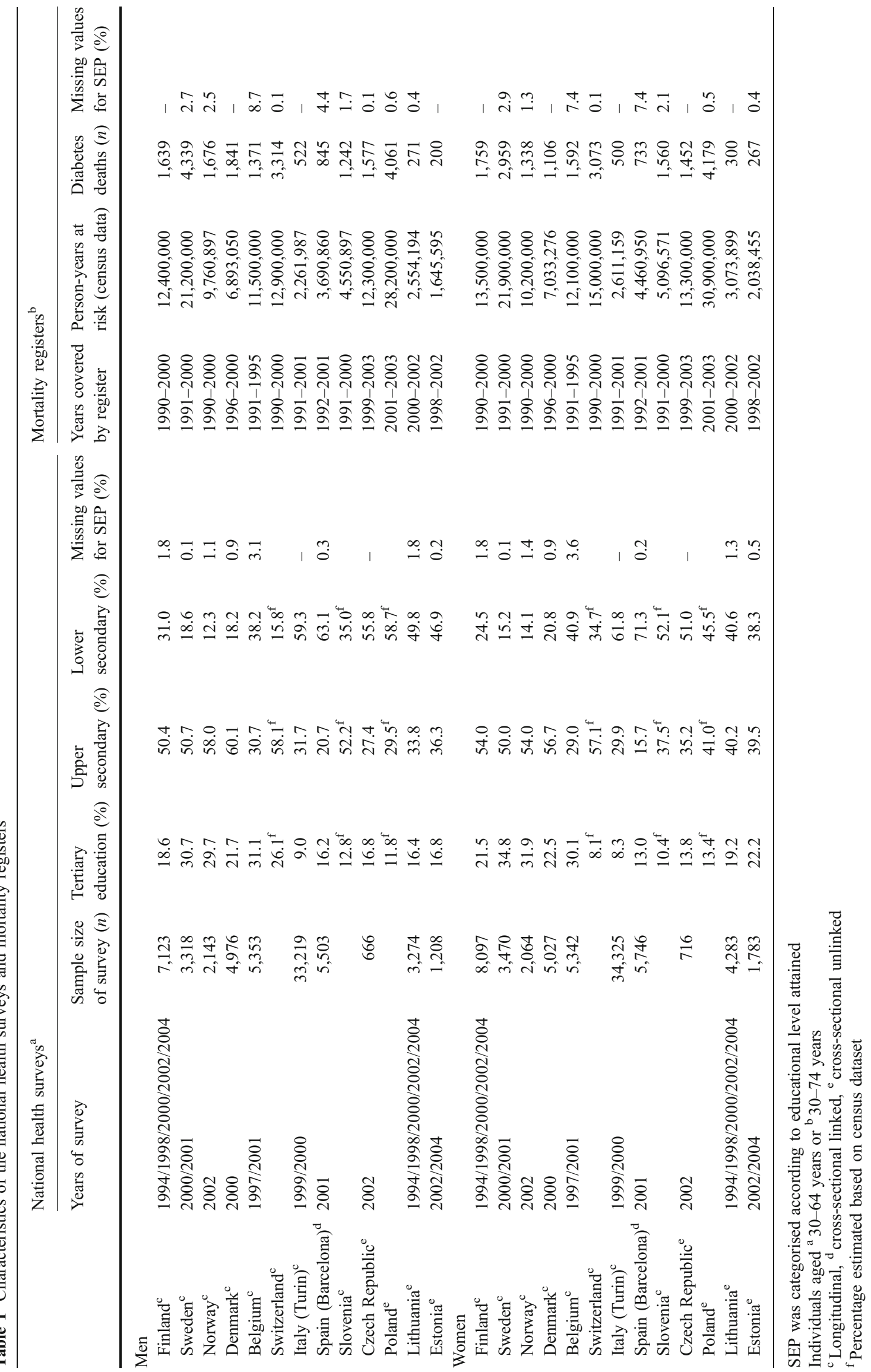


tional Classification of Diseases, 10th revision (ICD-10) classification system (http://www.who.int/classifications/ icd/en/). Each survey had either two ('yes', 'no') or three ('yes', 'have had', 'have never had') response categories. The percentage of missing values for this variable were below $1 \%$ for all countries except Lithuania (15.8\%), Estonia (4.4\%), Germany (3.9\%) and Belgium (1.1\%).

In terms of diabetes mortality, the underlying cause of death was coded using either the ICD-9 or ICD-10, depending on the country and the year; the relevant codes were ICD-9:250 and ICD-10:E10-E14.

Educational level (as an indicator of SEP) [1], age and sex were independent variables. Educational level was determined based on national education schemes reclassified into three categories according to the International Standard Classification of Education (ISCED), which was designed by the United Nations Educational, Scientific and Cultural Organization (UNESCO). The educational levels were lower secondary or less (ISCED 1-2), upper secondary (ISCED 3-4) and tertiary (ISCED 5-6). Missing values for educational level were $<4 \%$ in the morbidity and mortality datasets.

For the mortality data, the age recorded corresponded to the start of the follow-up in longitudinal studies and age at death in those with a cross-sectional design. Age was stratified according to 5 year intervals (see Table 1).

Data analysis For national health surveys a standardised weighting was used as necessary to take into account the sample design. Mortality data were stratified according to 5 year age group, sex and level of education.

All the analyses were performed separately for men and women [22] and for each country. First, all the variables for health surveys and for mortality registers were described. Age-standardised prevalence and mortality rates were then calculated by the direct method using the entire health surveys for ten countries and the whole census population at risk for the 13 sites included in the mortality study as standard populations.
For diabetes morbidity, log-binomial regression models were fitted to assess the associations between diabetes morbidity and SEP and age in each country. The associations with SEP are presented as age-adjusted prevalence ratios (PRs) and 95\% CIs.

For diabetes mortality, Poisson regression models were fitted to determine associations between mortality rates and educational level and age in each country. The person-years at risk were introduced as an offset. The associations with educational level are presented as age-adjusted RR and $95 \%$ CIs.

Finally, we created a pooled data set with the data of all populations, including population-specific weights assigned to the individual observations, so that the separate populations carried equal weight in the results for all populations combined. With this data set, we fitted a logBinomial regression and a Poisson regression model to assess the association between diabetes (morbidity and mortality) and educational level for all countries combined.

\section{Results}

Table 1 presents a description of the morbidity datasets (national health surveys) and a description of the mortality register in each setting for both men and women. It can be seen that for both men and women, the distribution of SEP varies according to country. Spain is the country with the highest percentage of individuals with an educational level of lower secondary or less $(63.1 \%$ of men, $71.3 \%$ of women) and Sweden is the country with the highest proportion of individuals with a high (tertiary) level of education (30.7\% of men, $34.8 \%$ of women).

For the countries together as a whole, inequalities in SEP were related to diabetes morbidity and mortality (Fig. 1). According to these data, the PR for a woman with a low SEP having diabetes is $2.2(95 \%$ CI $1.9-2.7)$, while for a man it is 1.6 (95\% CI 1.4-1.9). The RR of dying from
Fig. 1 Association of SEP (educational level attained) with diabetes morbidity (age-adjusted PR) (a) and diabetes mortality (age-adjusted RR) (b) for men (lines) and women (squares). The bars indicate the 95\% CI. Data are from all European settings studied
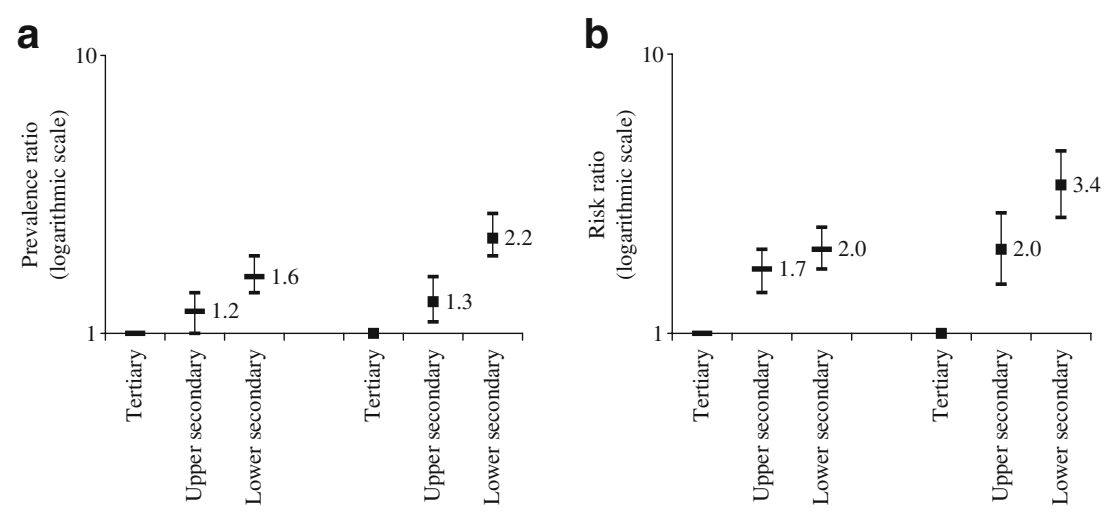
diabetes for women with a low SEP from all the countries is 3.4 (95\% CI 2.6-4.5), while for men it is 2.0 (95\% CI 1.72.4). Thus, SEP differences in diabetes are larger among women, both in terms of morbidity and mortality.

Morbidity from diabetes Morbidity from diabetes is described in Table 2. In all countries, having a disadvantaged SEP is related to a higher prevalence of diabetes. Moreover, there is an inverse relationship between educational level and prevalence of diabetes. In the majority of countries studied, the prevalence of diabetes among people with an advantaged SEP was around 2-3\% (range 1.5-5.4\% in men, $0.6-4.1 \%$ in women), and was higher, around $5 \%$ (range $2.5-8.5 \%$ in men, $2.7-8.8 \%$ in women) among people with a disadvantaged SEP. In both women and men these differences are more pronounced in Western countries, particularly Belgium and Italy. In men, the relationship between diabetes morbidity and SEP is only statistically significant in three countries (Norway, Belgium and Italy), whereas in women it is statistically significant in the majority of countries.

Mortality from diabetes Rates of mortality from diabetes are shown in Table 3. In all countries, having a disadvan- taged SEP is related to a higher rate of mortality from diabetes. Furthermore, as for morbidity, there is an inverse relationship between SEP and mortality. For the majority of countries, the RR of dying from diabetes is significantly higher for both men and women who occupy a low SEP than for those who occupy a high SEP. There are relatively large inequalities in Eastern European countries, particularly among women, with large differences between those with tertiary education and the rest of the population, and smaller differences between the mid and lower levels (i.e. the majority of the population). The RR of dying from diabetes in the Czech Republic is 7.82 (95\% CI 3.3-18.7) for women and 5.2 (95\% CI 1.9-14.0) for men, while the corresponding RRs in Sweden are 3.0 (95\% CI 1.9-4.8) and 2.2 (95\% CI 1.8-2.6), respectively. It should be noted that absolute differences between educational level rates are not very different between Western and Eastern European countries.

\section{Discussion}

The four main findings of this study are: (1) SEP inequalities are related to morbidity and mortality in diabetes mellitus in all countries, in a linear fashion, although

Table 2 Age-standardised prevalence and PR of diabetes by SEP (according to educational level attained)

\begin{tabular}{|c|c|c|c|c|c|}
\hline & \multicolumn{3}{|c|}{ Prevalence, $\%(95 \% \mathrm{CI})$} & \multicolumn{2}{|l|}{$\operatorname{PR}(95 \% \mathrm{CI})^{\mathrm{a}}$} \\
\hline & Tertiary education & Upper secondary & Lower secondary & Upper secondary & Lower secondary \\
\hline \multicolumn{6}{|l|}{ Men } \\
\hline Finland & $2.7(1.8-3.6)$ & $3.1(2.5-3.7)$ & $5.5(4.6-6.5)$ & $1.1(0.8-1.6)$ & $1.3(0.9-2.0)$ \\
\hline Sweden & $1.8(1.0-2.6)$ & $2.4(1.7-3.1)$ & $4.7(3.0-6.4)$ & $1.3(0.8-2.3)$ & $1.9(1.0-3.5)$ \\
\hline Norway & $1.9(0.8-3.0)$ & $3.0(2.1-4.0)$ & $6.9(3.8-10.0)$ & $1.6(0.8-3.0)$ & $3.2(1.6-6.4)^{*}$ \\
\hline Denmark & $1.8(0.9-2.6)$ & $2.4(1.8-2.9)$ & $3.5(2.2-4.8)$ & $1.3(0.7-2.1)$ & $1.7(0.9-3.1)$ \\
\hline Belgium & $1.5(0.9-2.1)$ & $2.1(1.4-2.8)$ & $4.4(3.5-5.3)$ & $1.4(0.8-2.3)$ & $2.2(1.4-3.5)^{*}$ \\
\hline Italy & $1.9(1.4-2.3)$ & $2.2(1.9-2.5)$ & $4.3(4.1-4.6)$ & $1.3(1.0-1.8)$ & $1.7(1.3-2.2)^{*}$ \\
\hline Spain & $2.7(1.6-3.8)$ & $1.8(1.0-2.5)$ & $4.9(4.2-5.6)$ & $0.7(0.4-1.3)$ & $1.3(0.8-1.9)$ \\
\hline Czech Republic & $5.4(1.2-9.5)$ & $4.4(1.4-7.4)$ & $8.5(5.5-11.2)$ & $0.7(0.3-2.0)$ & $1.2(0.5-2.8)$ \\
\hline Lithuania & $3.2(1.7-4.7)$ & $1.8(1.0-2.6)$ & $2.5(1.7-3.3)$ & $0.7(0.3-1.2)$ & $0.7(0.4-1.2)$ \\
\hline Estonia & $2.0(0.1-3.9)$ & $3.0(1.4-4.6)$ & $5.3(3.5-7.2)$ & $1.7(0.6-5.2)$ & $2.3(0.8-6.5)$ \\
\hline \multicolumn{6}{|l|}{ Women } \\
\hline Finland & $1.3(0.8-1.9)$ & $2.2(1.8-2.7)$ & $3.9(3.0-4.7)$ & $1.5(0.9-2.3)$ & $1.8(1.1-2.9)^{*}$ \\
\hline Sweden & $0.6(0.2-1.0)$ & $1.7(1.1-2.3)$ & $2.7(1.3-4.0)$ & $2.6(1.2-6.0)^{*}$ & $2.7(1.1-6.8)^{*}$ \\
\hline Norway & $1.5(0.6-2.5)$ & $3.0(2.0-4.0)$ & $4.9(2.4-7.4)$ & $1.8(0.9-3.5)$ & $2.2(1.0-5.0)$ \\
\hline Denmark & $1.3(0.6-2.0)$ & $1.6(1.1-2.1)$ & $3.5(2.4-4.7)$ & $1.2(0.6-2.2)$ & $1.9(1.0-3.7)$ \\
\hline Belgium & $1.2(0.7-1.8)$ & $2.0(1.3-2.7)$ & $4.6(3.7-5.5)$ & $1.5(0.9-2.7)$ & $2.7(1.7-4.5)^{*}$ \\
\hline Italy & $0.7(0.4-1.0)$ & $1.0(0.8-1.2)$ & $3.9(3.6-4.1)$ & $1.4(0.9-2.3)$ & $3.0(2.0-4.7)^{*}$ \\
\hline Spain & $1.1(0.3-1.8)$ & $0.8(0.2-1.4)$ & $5.1(4.5-5.8)$ & $0.8(0.3-2.1)$ & $2.7(1.3-5.5)^{*}$ \\
\hline Czech Republic & $4.1(0.2-8.0)$ & $2.0(0.3-3.7)$ & $8.8(5.9-11.7)$ & $0.5(0.1-1.7)$ & $1.5(0.6-4.3)$ \\
\hline Lithuania & $1.2(0.5-2.0)$ & $1.5(0.9-2.0)$ & $3.1(2.3-4.0)$ & $1.3(0.6-2.6)$ & $1.5(0.8-2.9)$ \\
\hline Estonia & $4.1(2.1-6.0)$ & $5.7(4.0-7.4)$ & $8.2(6.2-10.3)$ & $1.5(0.8-2.6)$ & $1.7(1.0-2.9)$ \\
\hline
\end{tabular}

Analysis of men and women aged 30-64 years at ten European sites

${ }^{a}$ Tertiary education was the reference category

$* p<0.05$ 
Table 3 Age-standardised diabetes mortality rate by SEP (according to educational level attained) and RR of mortality

\begin{tabular}{|c|c|c|c|c|c|}
\hline & \multicolumn{3}{|c|}{ Mortality rate per 100,000 inhabitants } & \multicolumn{2}{|l|}{$\operatorname{RR}(95 \% \mathrm{CI})^{\mathrm{a}}$} \\
\hline & Tertiary education & Upper secondary & Lower secondary & Upper secondary & Lower secondary \\
\hline \multicolumn{6}{|l|}{ Men } \\
\hline Finland & 9.6 & 14.4 & 18.3 & $1.6(1.2-2.2)^{*}$ & $2.0(1.5-2.6)^{*}$ \\
\hline Sweden & 11.4 & 14.6 & 23.9 & $1.3(1.1-1.7)^{*}$ & $2.2(1.8-2.6)^{*}$ \\
\hline Norway & 11.0 & 16.4 & 24.0 & $1.6(1.3-1.9)^{*}$ & $2.2(1.9-2.7)^{*}$ \\
\hline Denmark & 10.6 & 18.6 & 32.3 & $1.6(1.0-2.7)$ & $3.0(1.9-4.6)^{*}$ \\
\hline Belgium & 7.7 & 10.0 & 14.4 & $1.3(1.0-1.7)$ & $1.9(1.6-2.4)^{*}$ \\
\hline Switzerland & 17.5 & 26.8 & 37.9 & $1.6(1.4-1.8)^{*}$ & $2.2(1.9-2.5)^{*}$ \\
\hline Italy (Turin) & 19.1 & 17.1 & 27.1 & $1.0(0.6-1.5)$ & $1.5(1.0-2.1)^{*}$ \\
\hline Spain (Barcelona) & 17.8 & 18.1 & 24.1 & $1.0(0.8-1.4)$ & $1.4(1.1-1.7)^{*}$ \\
\hline Slovenia & 35.9 & 44.0 & 40.3 & $1.3(1.0-1.7)^{*}$ & $1.3(1.0-1.7)$ \\
\hline Czech Republic & 3.2 & 7.7 & 16.6 & $2.4(0.8-7.1)$ & $5.2(1.9-14.0)^{*}$ \\
\hline Poland & 7.0 & 12.9 & 18.5 & $1.8(1.3-2.5)^{*}$ & $2.7(2.0-3.7)^{*}$ \\
\hline Lithuania & 6.3 & 12.7 & 12.4 & $2.2(1.3-3.9)^{*}$ & $2.0(1.1-3.5)^{*}$ \\
\hline Estonia & 8.8 & 14.3 & 14.9 & $1.6(0.8-3.2)$ & $1.5(0.7-3.0)$ \\
\hline \multicolumn{6}{|l|}{ Women } \\
\hline Finland & 4.9 & 8.8 & 15.6 & $1.8(0.8-3.7)$ & $2.9(1.5-5.8)^{*}$ \\
\hline Sweden & 4.6 & 7.1 & 13.4 & $1.6(0.7-3.4)$ & $3.0(1.9-4.8)^{*}$ \\
\hline Norway & 5.4 & 8.8 & 15.5 & $1.7(1.2-2.5)^{*}$ & $2.9(2.0-4.2)^{*}$ \\
\hline Denmark & 6.9 & 7.6 & 16.7 & $0.9(0.3-2.6)$ & $2.0(0.7-5.5)$ \\
\hline Belgium & 4.8 & 5.9 & 13.9 & $1.2(0.6-2.6)$ & $2.8(1.5-5.2)^{*}$ \\
\hline Switzerland & 8.1 & 13.8 & 23.8 & $1.7(1.3-2.2)$ & $2.9(2.2-3.8)^{*}$ \\
\hline Italy (Turin) & 7.0 & 8.0 & 19.0 & $1.4(0.4-4.6)$ & $3.2(1.2-9.3)^{*}$ \\
\hline Spain (Barcelona) & 5.8 & 7.5 & 14.3 & $1.4(0.8-2.5)$ & $2.5(1.6-4.0)^{*}$ \\
\hline Slovenia & 8.4 & 27.8 & 36.7 & $3.3(1.5-7.1)^{*}$ & $4.3(2.0-9.1)^{*}$ \\
\hline Czech Republic & 1.5 & 4.9 & 11.0 & $3.3(1.4-8.2)^{*}$ & $7.8(3.3-18.7)^{*}$ \\
\hline Poland & 3.8 & 6.9 & 15.8 & $2.0(1.3-3.1)^{*}$ & $4.6(3.1-6.9)^{*}$ \\
\hline Lithuania & 1.1 & 7.8 & 15.9 & $6.6(1.7-26.4)^{*}$ & $10.7(2.7-42.4)^{*}$ \\
\hline Estonia & 3.6 & 11.1 & 16.4 & $3.2(1.8-5.8)^{*}$ & $4.1(2.3-7.5)^{*}$ \\
\hline
\end{tabular}

Analysis of men and women aged 30-74 years at 13 European sites

${ }^{a}$ Tertiary education was the reference category

${ }^{*} p<0.05$

differences in morbidity among men are relatively small; (2) SEP inequalities in diabetes prevalence are smaller than corresponding differences in diabetes mortality; (3) SEP inequalities in both morbidity and mortality are relatively higher among women than among men, particularly with respect to morbidity; and (4) relative inequalities in morbidity are more pronounced for Western European countries, whereas relative inequalities in mortality are greater in Eastern European countries. These patterns are not as clear when absolute differences between mortality and educational level rates are taken into account.

Limitations The data presented are subject to several limitations. First, as mentioned above, some Eastern European and Baltic countries, except Slovenia, are characterised by the use of a cross-sectional unlinked study design. Data for Slovenia were supplied from a censuslinked mortality follow-up and this country had smaller inequalities in mortality than the other Eastern European countries. While this may be taken to suggest bias caused by differences in study design, it is also possible that Slovenia has different characteristics to other Eastern European countries. Also, for some countries in Western Europe that supplied data from both unlinked crosssectional mortality studies and census-linked longitudinal mortality studies (e.g. England, France), it has been reported that differences between data obtained using the two study designs are not large and are not systematically in one direction [23]. Moreover, Shkolnikov et al. found that mortality inequalities based on unlinked mortality data in Lithuania were overestimated, mainly in the older age groups ( 70 years and above), limited overestimation in the group aged 30-69 years [24]. Thus, the possibility of overestimation mortality inequalities by education in Eastern and Baltic countries is probably reduced by the choice of age group studied here (30-74 years). 
Other limitations of this study are the under-recording of diabetes. Regarding the declaration of diabetes in health interview surveys, some studies have concluded that educational differences in misreporting of diabetes are small or absent [25]. Moreover, health surveys of diabetes only report diagnosed diabetes, which only represents between $30 \%$ and $50 \%$ of total diabetes [26, 27]. One study recently reported that socioeconomic status, as measured by education, is not associated with having undiagnosed diabetes [28]. Mackenbach et al concluded that the misreporting of diabetes varies according to the respondents' level of education as they found that health interview survey data underestimate socioeconomic inequalities in the prevalence of diabetes [29]. In this sense, this article provides a conservative estimate of diabetes inequalities. Another limitation of this study could be the under-reporting of diabetes mellitus in death certificates, but to our knowledge, there is no evidence that this under-reporting varies by SEP.

The measure of SEP used (educational level) presents several limitations: (1) its inability to refer to social groups arising from interdependent economic relationships; (2) it is less predictive than class position of ownership of capital assets; and (3) it does not have a universal meaning because its implications are related to age, sex, race, birth cohort and class position. However, educational level does have the advantage that it can be measured for everybody, it is easy to measure and has been related to many health outcomes [1].

Inequalities in diabetes morbidity and mortality in Europe Mackenbach et al., who studied inequalities in health in Europe [30], as part of the Tackling Health Inequalities in Europe (EUROTHINE) project, found that relative inequalities in mortality (all causes) were small in some southern European countries and very large in most countries in the Eastern and Baltic regions. This result is similar that of our study, which focused on diabetes inequalities. Wild et al. estimate that the worldwide prevalence of diabetes was $2.8 \%$ in the year 2000 and will be about $4.4 \%$ in the year 2030 [31]. These data are in accordance with our results. We found higher prevalences in Western countries, in accordance with Goday's review, which found a greater presence of diabetes mellitus in societies that do not have traditional lifestyles or have become industrialised over a relatively short period of time [32]. Moreover, in industrialised countries, there is a linear relationship between SEP and the prevalence of diabetes [3]. In our study we observed that socioeconomic health was inversely related to the prevalence of diabetes, both for each country analysed individually and for the overall data. In accordance with other studies we have found that diabetes morbidity is associated with having a disadvan- taged SEP [2, 3, 8-12]. Previous studies that have analysed inequalities in diabetes mortality also have shown that people with a lower SEP have a higher risk of dying from diabetes [13-15].

In this study we have shown how diabetes morbidity and mortality vary across countries. The different patterns observed probably depend on the particular characteristics of the country, such as availability of healthy foods, access to places to exercise, neighbourhood safety, transportation, environmental exposures and access to healthcare services [8], and possibly on the degree of general socioeconomic development (welfare state, social expenditure, labour force, power resources and wealth) [33, 34]. For example, if patients with diabetes who occupy a low SEP in Eastern countries have more restricted access to healthcare services than patients with the same SEP who reside in Western countries, this could explain the higher relative inequalities in mortality in Eastern Europe.

We have observed that SEP inequalities in diabetes were higher among women than among men. Some studies have confirmed that socioeconomic inequalities in the prevalence of common chronic diseases, including diabetes, are greater in women than in men $[3,35,36]$. This study supports these findings. Recent studies from different countries have reported similar results for diabetes mortality [35, 37]. This different pattern among women can be explained by the existence of inequalities in health behaviours, because people with a disadvantaged SEP have a higher prevalences of obesity, lower physical activity and high psychosocial risks, these inequalities being higher among women than among men [36, 38, 39]. Cavelaars et al. [40] reported that SEP inequalities in obesity in some European countries were higher among women.

Another important finding of this study is that inequalities in diabetes mortality are higher than inequalities in diabetes morbidity in the majority of countries. In this sense, it should be noted that when diabetes is diagnosed there are several factors related to disease progression that can widen the inequalities in diabetes mortality related to SEP. These factors are less access to and use of healthcare services and poorer quality of the care process, as well as lower levels of diabetes education and control of variables related to diabetes (e.g. glycaemia, weight, cholesterol) for patients that occupy a disadvantaged SEP [2, 8, 21].

Conclusions and recommendations In this study we have confirmed that there are important socioeconomic inequalities in diabetes morbidity and mortality in all European countries studied. It would be interesting to undertake another study including country contextual variables to determine how country characteristics affect diabetes morbidity and mortality and socioeconomic inequalities. 
Knowledge of how inequalities in diabetes mellitus differ between countries can be useful for the development of policies to reduce the incidence of the disease and to control mortality across the entire population. In this sense, health promotion and access for everybody (particularly disadvantaged people) to healthy behaviours, such as healthy foods and places to exercise, are all important. Improving access to healthcare services for the whole population and people with diabetes in particular, would also improve the control of patients with diabetes. Moreover, it may be helpful to evaluate the effect of different public policies designed to diminish social class inequalities in diabetes.

Acknowledgements This investigation was funded by the Health and Consumer Protection Directorate-General of the European Union and was carried out as a part of the Eurothine project (grant number 2003125). The help of D. Macfarlane of the Institut Municipal d'Investigació Mèdica (IMIM), L. Espelt of the Universitat de Lleida (UdL) (English revision) and L. Font of the Centre for Research in Environmental Epidemiology (CREAL) (who provided comments on a previous version) during the writing of this article is much appreciated. We are also grateful for the comments made by A. Goday of the Institut Municipal d'Assistència Sanitària (IMAS). This article forms part of the doctoral dissertation of A. Espelt at the Universitat Pompeu Fabra.

Duality of interest The authors declare that there is no duality of interest associated with this manuscript.

\section{References}

1. Krieger N, Williams DR, Moss NE (1997) Measuring social class in US public health research: concepts, methodologies, and guidelines. Annu Rev Public Health 18:341-378

2. Larranaga I, Arteagoitia JM, Rodriguez JL, Gonzalez F, Esnaola S, Pinies JA (2005) Socio-economic inequalities in the prevalence of type 2 diabetes, cardiovascular risk factors and chronic diabetic complications in the Basque Country, Spain. Diabet Med 22:1047-1053

3. Dalstra JA, Kunst AE, Borrell C et al (2005) Socioeconomic differences in the prevalence of common chronic diseases: an overview of eight European countries. Int J Epidemiol 34:316-326

4. Avendano M, Kunst AE, van Lenthe F et al (2005) Trends in socioeconomic disparities in stroke mortality in six European countries between 1981-1985 and 1991-1995. Am J Epidemiol 161:52-61

5. Avendano M, Kunst AE, Huisman M et al (2006) Socioeconomic status and ischaemic heart disease mortality in 10 western European populations during the 1990s. Heart 92:461-467

6. Huisman M, Kunst AE, Bopp M et al (2005) Educational inequalities in cause-specific mortality in middle-aged and older men and women in eight western European populations. Lancet 365:493-500

7. Solar O, Irwin A (2007) A conceptual framework for action on the social determinants of health. WHO (Commission on Social Determinants of Health), Geneva

8. Brown AF, Ettner SL, Piette J et al (2004) Socioeconomic position and health among persons with diabetes mellitus: a conceptual framework and review of the literature. Epidemiol Rev 26:63-77

9. Abu Saveed M, Ali L, Hussain MZ, Rumi MA, Banu A, Azad Khan AK (1997) Effect of socioeconomic risk factors on the difference in prevalence of diabetes between rural and urban populations in Bangladesh. Diabetes Care 20:551-555

10. Connolly V, Unwin N, Sherriff P, Bilous R, Kelly W (2000) Diabetes prevalence and socioeconomic status: a population based study showing increased prevalence of type 2 diabetes mellitus in deprived areas. J Epidemiol Community Health 54:173-177

11. Kumari M, Head J, Marmot M (2004) Prospective study of social and other risk factors for incidence of type 2 diabetes in the Whitehall II study. Arch Intern Med 164:1873-1880

12. Wray LA, Alwin DF, McCammon RJ, Manning T, Best LE (2006) Social status, risky health behaviors, and diabetes in middle-aged and older adults. J Gerontol B Psychol Sci Soc Sci 61:S290-S298

13. Laing SP, Jones ME, Swerdlow AJ, Burden AC, Gatling W (2005) Psychosocial and socioeconomic risk factors for premature death in young people with type 1 diabetes. Diabetes Care 28:1618-1623

14. Lawlor DA, Sterne JA, Tynelius P, Davey SG, Rasmussen F (2006) Association of childhood socioeconomic position with cause-specific mortality in a prospective record linkage study of 1,839,384 individuals. Am J Epidemiol 164:907-915

15. Wilder RP (2003) Education and mortality in type 2 diabetes. Diabetes Care 26:1650

16. De Cosmo S, Lamacchia O, Rauseo A et al (2006) Cigarette smoking is associated with low glomerular filtration rate in male patients with type 2 diabetes. Diabetes Care 29:2467-2470

17. Choi HK, Willett WC, Stampfer MJ, Rimm E, Hu FB (2005) Dairy consumption and risk of type 2 diabetes mellitus in men: a prospective study. Arch Intern Med 165:997-1003

18. Ekoe J, Shipp J (2001) Type 2 diabetes and obesity. In: Ekoe J, Zimmet P, Williams R (eds) The epidemiology of diabetes mellitus. Wiley, Chichester, pp 273-285

19. Gutiérrez-Fisac JL, Regidor E, Banegas Banegas J, Rodríguez Artalejo F (2007) The size of obesity differences associated with educational level in Spain, 1987 and 1995/97. J Epidemiol Community Health 56:457-460

20. Shahar D, Shai I, Vardi H, Shahar A, Fraser D (2005) Diet and eating habits in high and low socioeconomic groups. Nutrition 21:559-566

21. Reisig V, Reitmeir P, Doring A, Rathmann W, Mielck A (2007) Social inequalities and outcomes in type 2 diabetes in the German region of Augsburg. A cross-sectional survey. Int J Public Health $52: 158-165$

22. Kunkel SR, Atchley RC (1996) Why gender matters: being female is not the same as not being male. Am J Prev Med 12:294-296

23. Kunst AE (1997) Cross-national comparisons of socioeconomic differences in mortality. Erasmus University, Rotterdam

24. Shkolnikov VM, Jasilionis D, Andreev EM, Jdanov DA, Stankuniene V, Ambrozaitiene D (2007) Linked versus unlinked estimates of mortality and length of life by education and marital status: evidence from the first record linkage study in Lithuania. Soc Sci Med 64:1392-1406

25. Waugh NR, Dallas JH, Jung RT, Newton RW (1989) Mortality in a cohort of diabetic patients. Causes and relative risks. Diabetologia 32:103-104

26. Rathmann W, Haastert B, Icks A et al (2003) High prevalence of undiagnosed diabetes mellitus in Southern Germany: target populations for efficient screening. The KORA survey 2000. Diabetologia 46:182-189

27. Franse LV, Di BM, Shorr RI et al (2001) Type 2 diabetes in older well-functioning people: who is undiagnosed? Data from the health, aging, and body composition study. Diabetes Care 24:2065-2070 
28. Wilder RP, Majumdar SR, Klarenbach SW, Jacobs P (2005) Socio-economic status and undiagnosed diabetes. Diabetes Res Clin Pract 70:26-30

29. Mackenbach JP, Looman CW, van der Meer JB (1996) Differences in the misreporting of chronic conditions, by level of education: the effect on inequalities in prevalence rates. Am J Public Health 86:706-711

30. Mackenbach JP, Stirbu I, Roskam AJ et al (2008) Socioeconomic inequalities in health in 22 European countries. N Engl J Med 358:2468-2481

31. Wild S, Roglic G, Green A, Sicree R, King H (2004) Global prevalence of diabetes: estimates for the year 2000 and projections for 2030. Diabetes Care 27:1047-1053

32. Goday A (2002) Epidemiology of diabetes and its non-coronary complications. Rev Esp Cardiol 55:657-670 (article in Spanish)

33. Borrell C, Espelt A, Rodriguez-Sanz M (2007) Politics and Health. J Epidemiol Community Health 61:658-659

34. Navarro V, Muntaner C, Borrell C et al (2006) Politics and health outcomes. Lancet 368:1033-1037
35. Borrell C, Azlor E, Rodríguez-Sanz M et al (2007) Trends in socioeconomic mortality inequalities in a southern urban setting at the turn of the century. J Epidemiol Community Health 62:258-266

36. Tang M, Chen Y, Krewski D (2003) Gender-related differences in the association between socioeconomic status and self-reported diabetes. Int J Epidemiol 32:381-385

37. Turrell G, Mathers C (2001) Socioeconomic inequalities in allcause and specific-cause mortality in Australia: 1985-1987 and 1995-1997. Int J Epidemiol 30:231-239

38. Loucks EB, Rehkopf DH, Thurston RC, Kawachi I (2007) Socioeconomic disparities in metabolic syndrome differ by gender: evidence from NHANES III. Ann Epidemiol 17:19-26

39. Thurston RC, Kubzansky LD, Kawachi I, Berkman LF (2005) Is the association between socioeconomic position and coronary heart disease stronger in women than in men? Am J Epidemiol 162:57-65

40. Cavelaars A, Kunst A, Mackenbach JP (1997) Socio-economic differences in risk factors for morbidity and mortality in the European Community: an international comparison. J Health Psychol 2:353-372 